\title{
Body Size from Birth through Adolescence in Relation to Risk of Benign Breast Disease in Young Women
}

\author{
Catherine S. Berkey ${ }^{1}$, Bernard Rosner ${ }^{1}$, Rulla M. Tamimi ${ }^{1}$, Walter C. Willett ${ }^{2}$, Martha \\ Hickey $^{3}$, Adetunji Toriola ${ }^{4}$, A. Lindsay Frazier ${ }^{5}$, and Graham A. Colditz 6 \\ ${ }^{1}$ Channing Division of Network Medicine, Department of Medicine, Brigham \& Women's Hospital \\ and Harvard Medical School \\ ${ }^{2}$ Departments of Nutrition and Epidemiology, Harvard T.H. Chan School of Public Health \\ ${ }^{3}$ Department of Obstetrics and Gynaecology, University of Melbourne and The Royal Women's \\ Hospital, Melbourne, Australia \\ ${ }^{4}$ Division of Public Health Sciences, Department of Surgery, Washington University School of \\ Medicine, and Alvin J Siteman Cancer Center, St. Louis, MO \\ ${ }^{5}$ Department of Pediatric Oncology, Dana-Farber Cancer Institute \\ ${ }^{6}$ Alvin J. Siteman Cancer Center, Washington University School of Medicine, St. Louis, MO
}

\section{Abstract}

Purpose-Body size, from birth throughout adulthood, is associated with breast cancer risk, but few studies have investigated early life body size and benign breast disease (BBD), a wellestablished breast cancer risk factor. We consider whether prenatal factors and size at birth, $10 \mathrm{yr}$, $18 \mathrm{yr}$, and intervening growth, are related to BBD risk.

Methods-The Growing Up Today Study includes 9032 females who completed questionnaires annually from 1996-2001, then 2003, 2005, 2007, 2010, 2013. In 1996, their mothers provided pregnancy-related data. From 2005-2013, participants (18yr+) reported whether they had ever been diagnosed with biopsy-confirmed BBD ( $\mathrm{N}=142$ cases).

Results-Girls had greater adiposity $\left(\mathrm{BMI} ; \mathrm{kg} / \mathrm{m}^{2}\right)$ at $10 \mathrm{yr}$ if they were larger at birth, if mother's pre-pregnancy BMI was higher, or if gestational weight gain was greater (all $\mathrm{p}<.01$ ). Maternal height was (positively) associated ( $\mathrm{p}<.05)$ with adolescent peak height growth velocity (PHV;inch/ yr). Greater 10yr adiposity was associated with lower PHV and less height growth 10-18yr (both $\mathrm{p}<.01)$. Adiposity at $10 \mathrm{yr}$ was inversely associated with $\mathrm{BBD}\left(\mathrm{OR}=0.83 /\left(\mathrm{kg} / \mathrm{m}^{2}\right), \mathrm{p}<.01\right)$ as was

\footnotetext{
Corresponding Author: Dr. Catherine S. Berkey, Channing Division, 181 Longwood Avenue, Boston, MA 02115. Phone: 617-525-0845. FAX: 617-525-2008. Catherine.Berkey@ channing.harvard.edu.

Ethical Approval

All procedures were in accordance with the ethical standards of Harvard University and Brigham \& Women's Hospital, and with the 1964 Helsinki declaration.

Informed Consent

Informed consent was obtained from all individual participants included in this study.

Conflict of Interest

The authors declare that they have no conflict of interest.
} 
increasing adiposity $10-18 \mathrm{yr}\left(\mathrm{OR}=0.85 /\left(\mathrm{kg} / \mathrm{m}^{2}\right), \mathrm{p}=.01\right)$. In a separate model, $10 \mathrm{yr}$ height $(\mathrm{OR}=1.13 / \mathrm{inch}, \mathrm{p}=.02)$ and height growth $10-18 \mathrm{yr}(\mathrm{OR}=1.19 / \mathrm{inch} ; \mathrm{p}<.01)$ were positively associated. PHV was similarly positively associated $(\mathrm{OR}=2.58, \mathrm{p}=.01$, fastest versus slowest growth quartiles). In a multivariable model of BBD risk, gestational weight gain (daughters at highest risk if $<20$ pounds gained), PHV (slowest growing girls at lowest risk), age 10yr height (positive) and BMI (inverse) were the most critical childhood risk factors (each $\mathrm{p}<.05$ ).

Conclusions-Body size factors from pregnancy through adolescence were independently associated with BBD risk in young women.

\section{Keywords}

maternal pre-pregnancy BMI; gestational weight gain; prenatal; birth weight; childhood adiposity; height growth

\section{Introduction}

Substantial evidence implicates the period before the first full term pregnancy, when mammary gland cells are undergoing rapid proliferation, as a critical time for exposures that may increase lifetime risk for breast cancer (BC) [1]. Some childhood and adolescent exposures are more important than adult exposures in $\mathrm{BC}$ development [2-5], so prevention efforts must begin early [6]. The hypothesis that $\mathrm{BC}$ may originate in utero [7], when differentiation of offspring mammary glands is ongoing, has been supported by animal studies [8]. Both animal and human studies suggest mechanisms whereby in utero, childhood and adolescent exposures influence cancer risk in women [9].

An impressive body of literature links high birth weight to increased risk of premenopausal $\mathrm{BC}$ [10]. Elevated BC risk has also been noted with higher birth length [11]. Maternal prepregnancy weight and gestational weight gain were not associated with $\mathrm{BC}$ in daughters [12]. A review article, acknowledging inconsistencies in the literature, concluded there is increased risk for females of lower gestational age, yet with greater birth weight and length [13]. However, after birth the direction of the association changes, and by 5yr body fatness is associated (independent of adult BMI) with lower risk of premenopausal and postmenopausal BC [14]. A recent investigation found that weight at $10 \mathrm{yr}$ and weight change to age 18yr were inversely related to lifetime risk [15]; however, weight gains after $18 \mathrm{yr}$ were instead associated with higher lifetime risk. Other studies suggested that more rapid childhood height growth may be a factor in the development of cancer, especially BC [5,16-17]. One theory is that adiposity in girls might reduce BC risk by suppressing later height growth, thus reducing DNA damage or facilitating DNA repair [1].

Because benign breast disease (BBD) is a well-established risk factor for BC [18], the investigation of exposures in girls and their subsequent development of BBD may provide insight into the etiology of $\mathrm{BC}$ and present possible new strategies for prevention. A previous investigation of fetal and infant factors, in which nurses (aged 27-44) self-reported their own birth weights, found no association with proliferative BBD [19]. In a cohort of females born after 1980, with pregnancy data reported by their mothers, we similarly found no association between birth weight and BBD in young women [20]. However, girls whose 
mothers' pre-pregnancy BMI was below $20 \mathrm{~kg} / \mathrm{m}^{2}$, and girls whose mothers gained less than 20 pounds during pregnancy, were at higher risk [20]. When these girls were age 9yrs and older, higher BMI and less intense height growth spurt were linked to lower risk of BBD [21].

This work has three purposes. First, parallel with a study of invasive BC [15], we investigate the associations of $10 \mathrm{yr}$ body size, and change from $10 \mathrm{yr}$ to $18 \mathrm{yr}$, with biopsy-confirmed BBD in young women. Second, because we have data from very early life, we can simultaneously analyze factors from the prenatal period up through $18 \mathrm{yr}$, in relation to BBD risk. Finally, by considering associations among these body size factors from different periods of life, we attempt to understand why childhood adiposity seems to protect against BBD and BC. The females in our cohort were born between 1980 and 1987, and disease follow-up is ongoing.

\section{Materials and Methods}

\section{Study Population}

The Growing Up Today Study (GUTS) includes 9032 girls from 50 states who are daughters of Nurses' Health Study II (NHSII) participants [22]. The study, approved by Institutional Review Boards at Harvard T.H. Chan School of Public Health and Brigham and Women's Hospital, is described elsewhere [23]. Mothers provided informed consent, and their 9-15 yr old daughters assented by completing baseline questionnaires in 1996. The cohort returned questionnaires annually (mail or Internet) through 2001, then in 2003, 2005, 2007, 2010, and 2013. The response rate to one or more follow-ups after baseline was $97 \%$. Over $81 \%$ returned at least one of the 2005 through 2013 surveys inquiring about BBD. At baseline, participants reported their race/ethnic group; $95 \%$ are white/non-Hispanic.

\section{Benign Breast Disease}

The 2005, 2007, 2010, and 2013 surveys inquired "Has a health care provider ever diagnosed you as having Benign Breast Disease?" and, if yes, whether it had been "Confirmed by breast biopsy". A total of 7298 females (18-32yr) reported whether a health care provider ever diagnosed them with BBD ( $\mathrm{n}=334$ said yes), and if any diagnosis had been confirmed by breast biopsy $(n=142)$. After excluding six girls whose mothers reported childhood cancer, 6958 females who returned surveys 2005-2013 but never reported BBD provide the non-cases for our BBD analyses.

Most BBD cases were likely diagnosed because participants (or physicians) found a clinically palpable mass, which was biopsied, since participants were too young for routine screening mammography. The most common type of BBD in adolescents and young women is fibroadenoma, accounting for nearly $70 \%$ of benign breast lesions; the remaining types are primarily cysts and fibrocystic changes [24]. A validation study in 621 NHSII women confirmed the accuracy (95\%) of self-reported biopsy-confirmed BBD [25]. 


\section{Early Life Factors: Pre-Pregnancy through Birth}

In 1996 mothers reported, for their daughters born during the previous decade, birth weight (pounds, ounces), birth length (inches), gestational age (full term, 1-2 weeks early, 3-6 weeks early, >6 weeks early), and height (feet, inches) of the biological father. Our 1999 survey to the mothers asked "How much did you weigh before this pregnancy?" and "How much weight did you gain during this pregnancy?".

Regarding validity, recollections of 154 women's pregnancy-related events, from $230 \mathrm{yrs}$ earlier, were compared to data collected at the time of their pregnancies [26]. Their recalls were highly accurate for pre-pregnancy weight $(\mathrm{r}=0.86)$ and birth-weight of their infants $(\mathrm{r}=0.91)$. Another validation study [27] compared maternal reports (30yrs later) of infants' birth-weights with state birth records and found $\mathrm{r}=0.85$. Maternal recalls, 4-12yrs after delivery, of weight gain during pregnancy agreed moderately well $(\mathrm{r}=0.63)$ with medicalrecords [28]. Because our early life data were recalled ( $9+$ yrs after childbirth) by mothers who were nurses, we expect a high degree of validity.

\section{Factors from Older Childhood and Adolescence}

Height, Weight, Adiposity-Children reported their heights and weights on each survey, beginning in 1996. Our questionnaire provided specific measuring instructions but suggested that they seek assistance; their own mothers self-reported their weights and height for NHSII [22]. An analysis of NHANES III adolescents indicated high validity for self-reported height $(\mathrm{r}=0.82)$ and weight $(\mathrm{r}=0.90)$ [29]. We assessed relative weight status by computing body mass index $\left(\mathrm{BMI}=\right.$ weight $\left./ \mathrm{height}^{2},\left(\mathrm{~kg} / \mathrm{m}^{2}\right)\right)$. National Longitudinal Study of Adolescent Health analyses that found high correlation $(\mathrm{r}=0.92)$ between BMI computed from measured values and from self-reports of height and weight by youth in grades 7-12 [30].

We obtained body height, weight and BMI from surveys the girls returned when they were $10 \mathrm{yr}$; if no survey was returned at age 10, we used the closest survey at $9 \mathrm{yr}$ or $11 \mathrm{yr}$; analyses adjusted for the exact age (months) when the survey was returned. We further assessed 10yr adiposity using the validated Stunkard body figure pictogram [31], consisting of 9 figures representing somatotype from thinnest to heaviest (see Fig 1 in [14]). The correlation between BMI and pictograms, both provided at $10 \mathrm{yr}$, was $\mathrm{r}=0.71$, higher than in a validation study ( $\mathrm{r}=0.65$ ) in which BMI's were measured in childhood but pictograms were recalled much later in adulthood [32]. Girls with 10yr data $(\mathrm{N}=4455)$ are a subset of our full cohort because many were older at baseline (up to $15 \mathrm{yr}$ ).

From later surveys, we obtained adult height, (non-pregnant) weight and BMI at $18 \mathrm{yr}$. Change in height, weight and BMI from 10 to $18 \mathrm{yr}$ were computed as the $18 \mathrm{yr}$ measurement minus that obtained at $10 \mathrm{yr}$, adjusted for exact (to the month) intervening time period.

The derivation of peak height growth velocity (PHV;inches/yr) was described earlier [21]. Because some girls were older at baseline (to 15yr), many had completed their height growth so we cannot estimate PHV from their annual heights, leaving us with 4999 girls with estimates of PHV and age when the growth spurt occurred (PKAGE). Our mean PHV of 3.22inch/yr is comparable to means from several earlier cohorts that derived PHV from heights measured by study personnel [33-35]. 


\section{Other Variables}

We computed ages (to month) from dates of questionnaire return and birth. Our early surveys annually asked "Have you started having menstrual periods?" and "If yes, age when periods began". Later surveys asked if the participants were, or had recently been, pregnant. Participants' mothers provided information regarding their own diagnoses of breast cancer and biopsy-confirmed BBD.

\section{Statistical Analyses}

Logistic regression models provided odds ratios (OR) and 95\% confidence intervals (CI) for biopsy-confirmed BBD [36]. Because age was related to each participant's chance of being diagnosed during follow-up, all models adjusted for age (to month) at cohort initiation. We first fit a series of models with body size exposures (BMI, height, or weight) at 10yr with change in same exposure size from 10-18yr. Because PHV is positively correlated with height growth from 10 to $18 \mathrm{yrs}$, another model related PHV to BBD risk. Finally, multivariable models included together factors from very early life previously found to influence risk of BC (birth weight) or BBD (gestational weight gain, maternal pre-pregnancy BMI), along with body size and growth in older children. These models adjusted for maternal history of BC and BBD, and for multiple births and gestational age since they impact birth weight. Models were fit using continuous measures (e.g. height in inches), and other models used 3-level categorical versions of each continuous exposure, to consider nonlinear associations. Tests for trend $\left(\mathrm{P}_{\mathrm{t}}\right)$ in categorized exposures were performed by using the median exposure value, within each category, as a continuous variable.

Because adiposity in girls is associated with lower risk of BBD and BC, we further used linear regression models to investigate how childhood adiposity affects subsequent growth, and similarly how the earliest (in utero and birth) factors affect body size at $10 \mathrm{yr}$ and subsequent growth.

\section{Results}

Over $81 \%$ of females returned at least one survey, from 2005-2013, containing BBD questions. Comparing early data of these participants with those who returned none, we found only very small differences. For example, included girls were slightly younger (5.8 weeks), but early life factors (maternal pre-pregnancy BMI, gestational weight gain, birth size) and 10yr body size (height, weight, BMI, pictogram) were similar for the included and missing females. The small age difference is unlikely to be a source of bias in our investigation of BBD risk factors.

Table 1 presents means or percents, within tertile of BMI at 10yr, of exposures and other important characteristics. Girls with higher 10yr BMIs had slower PHV and earlier menarche; though they were taller at $10 \mathrm{yr}$, they had less total growth after $10 \mathrm{yr}$, so that adult heights were similar. The thinnest $10 \mathrm{yr}$ olds were more likely to receive a BBD diagnosis (2.2\%). Regarding family history, the thinnest 10 -yr olds tended to have fewer mothers with breast cancer (4.6\%), but the heaviest 10-yr olds had lowest maternal BBD rates (15.6\%). 
In BBD analyses parallel with a BC investigation [15], adiposity at 10yr was inversely associated with BBD in young women $\left(\mathrm{OR}=0.83 /\left(\mathrm{kg} / \mathrm{m}^{2}\right), \mathrm{p}=.002\right)$ as was increase in adiposity from 10 to $18 \mathrm{yr}\left(\mathrm{OR}=0.85 /\left(\mathrm{kg} / \mathrm{m}^{2}\right), \mathrm{p}=.01\right)$ (Table 2 Model 1 ; both factors in model). In Model 2, 10yr weight (OR=0.84/(10 lbs); $=.04)$ was linked to lower risk, but subsequent weight change to $18 \mathrm{yr}$ was not $(\mathrm{OR}=0.96 /(10 \mathrm{lbs}) ; \mathrm{p}=.58)$. Model 3 showed that $10 \mathrm{yr}$ height $(\mathrm{OR}=1.13 / \mathrm{inch}, \mathrm{p}=.02)$ and height growth from 10-18yr $(\mathrm{OR}=1.19 / \mathrm{inch} ; \mathrm{p}=.002)$ were associated with higher BBD risk. Total height growth from 10yr to adulthood is correlated $(\mathrm{r}=0.37)$ with PHV, which is similarly associated with $\mathrm{BBD}(\mathrm{OR}=2.58, \mathrm{p}=.01$, most rapid growth quartile compared to slowest quartile; not shown), adjusted for 10yr height.

To understand how these childhood body size factors interact, Table 3 shows that higher $10 \mathrm{yr}$ BMI is associated with lower PHV and with less height growth from 10yr to adulthood (both $\mathrm{p}<.01$ ). Age $10 \mathrm{BMI}$ is also significantly associated with earlier menarche and earlier age at PHV, but it has no association with adult height. For body shape pictograms (rather than BMI) at 10yr, results are similar (Table 3). The inverse associations between childhood adiposity (BMI and pictogram) and PHV are even stronger when analyzing BMI (or pictogram) two, or separately three, years before age at PHV (Table 3). Adiposity immediately before peak growth (Table 3 ) is likely within the trajectory of the adolescent growth spurt and thus is, at least partly, a result of, rather than a cause, of growth velocity.

We further investigated earlier-life body size factors, to see their relation to body size at 10yr and subsequent growth (Table 4). Girls had higher BMIs at 10yr if they were larger at birth (length, weight, BMI), if gestational weight gain was greater, or if mother's pre-pregnancy BMI was higher (all $\mathrm{p} \leq 01$ ), but maternal and paternal height were not associated. Regarding PHV, only maternal height was (positively) associated ( $\mathrm{p}<.05)$. However, total height growth from 10-18yr was associated with many of the early-life factors, and with parental heights (Table 4). BMI change from 10-18yr was (positively) associated only with maternal prepregnancy BMI.

To simultaneously investigate body size factors from gestation throughout adolescence, and BBD risk, we put key factors into a single multivariable model (Table 5, Model 1). As reported previously [20], mothers who gained $\geq 20$ pounds during pregnancy had daughters with significantly lower risk, and girls with slowest PHV were also at significantly lower risk [21] (both factors were nonlinearly associated with BBD). BMI at 10yr was inversely associated with risk $(\mathrm{p}<.10)$. Birth weight had no association with BBD, nor did it modify associations with later adiposity (BMI at 10yr, BMI at 18yr) (not shown). Maternal prepregnancy BMI, which is moderately correlated with daughter's BMI at ages $10 \mathrm{yr}(\mathrm{r}=0.30)$ and 18yr ( $\mathrm{r}=0.35)$, was not significant. Further adjusting Model 1 for age 10yr physical activity did not materially affect any of the estimates (including age 10yr BMI), nor was physical activity itself associated with BBD [37].

When we analyzed BMI at 18yr in place of BMI at age 10 (Model 2, Table 5), the significant nonlinear associations of gestational weight gain and PHV persisted. When BMI at $18 \mathrm{yr}$ was then replaced by total height growth from 10 to $18 \mathrm{yr}$ (Model 3, Table 5), PHV was still significant (nonlinear) while height growth from 10 to 18yr was not. In Model 4, both adult 
height (positive) and age $18 \mathrm{BMI}$ (inverse) are significant risk factors for BBD, consistent with the BC literature.

Our final mutually-adjusted model (Model 5, Table 5) combined the most important factors from Table 2 (Models 1 and 3) and from Table 5 (Model 1). Though categorized changes in BMI and in height from 10 to $18 \mathrm{yr}$ were no longer statistically significant, the other factors continued to be associated with BBD. Comparing the top quartile to the bottom quartile of each factor, for age 10yr BMI OR=0.44 ( $\mathrm{p}=.02)$, for 10yr height $\mathrm{OR}=3.14(\mathrm{p}=.04)$, for PHV $\mathrm{OR}=2.20(\mathrm{p}=.047)$, and for gestational weight gain $\mathrm{OR}=0.53(\mathrm{p}=.03)$ for $>35$ pounds vs $<20$ pounds. For the latter two factors, associations with BBD are nonlinear. Even though greater adiposity at 10yr is associated with lower PHV (Table 3), this model suggests that they are independent risk factors for BBD.

\section{Discussion}

In a prospective investigation of body size factors, BBD risk in young women was inversely related to 10yr BMI and weight, and with change in BMI from 10 to $18 \mathrm{yr}$, while risk was positively related to age $10 \mathrm{yr}$ height, subsequent total height growth, and with PHV. Multivariable models, that included together body size factors from the prenatal period through adolescence, indicated that the inverse association of gestational weight gain [20] and the positive association of PHV [21] with BBD persisted, while the effect of maternal pre-pregnancy BMI [20] was diminished. In spite of strong evidence that birth weight is associated with $\mathrm{BC}$ [10], we found no evidence that it is associated with BBD; in addition to investigating an intermediate disease outcome (BBD) rather than the final outcome (BC), our cohort was born more recently than women in studies of BC.

Our multivariable analyses are important because there are many associations among factors from earliest-life and through adolescence; higher birth-weight (which increases BC risk [10]) predicts greater risk of obesity in adolescence [38], yet being heavier in childhood and adolescence is associated with lower risk for BBD [21] and BC [14]. Apparent inconsistencies such as these may reflect different pathways to disease. Other research (using mothers who in 2001 recalled information regarding their own pregnancies from 1946 to 1964) found a positive association between pre-pregnancy BMI and obesity in their daughters at age 18yr, and a U-shape association between gestational weight gain and obesity in daughters [39], both consistent with our data. Our finding that 10yr adiposity was inversely associated with PHV is consistent with work on a different cohort [33], in which BMI at 5yr was inversely associated with PHV.

Our BBD findings are consistent with the only previous investigation of very early life exposures [19], in which women $27 \mathrm{yr}$ and older self-reported their own birth weight, and no association was found with proliferative BBD. Also consistent with our findings at 10yr, they reported a strong inverse association with 5yr childhood body fatness and BBD [19]. Furthermore, our BBD findings are consistent with studies suggesting that height growth during ages 8-14yr [16], ages 4-7 and 11-15yr [17], and PHV [5,16] are associated with increased BC risk. Whether the most rapid growth itself, and how it may impact DNA damage and repair [1], or related factors, such as dietary intakes or hormones that promote 
growth, are cancer initiators/promoters is unknown. The potential role and interplay between growth hormones, IGF-I and estrogen may suggest a biological mechanism; the liver is a major source of IGF-I, growth hormones provide the main stimulus for hepatic IGF-I production, and estrogen also impacts growth hormone secretion [40-41]. Regarding genes, LIN28B influences childhood height growth, puberty and cancer progression [42], and a variant near ADCY3-POMC is associated with increased childhood body mass index, reduced pubertal growth and earlier puberty [42]. Interestingly, this is consistent with our findings since our girls with higher age 10yr BMI had lower PHV and earlier age at growth spurt and menarche.

Baer [14] discusses possible mechanisms for the lifetime protection against BC afforded by childhood adiposity. Though subsequent slower adolescent height growth may result in less DNA damage, lifetime protection from childhood adiposity may alternatively be through its influence on breast density [43-44]. Alternatively, genes that are related to BMI trajectories, driven by changes in weight rather than height, during childhood and adolescence [45], potentially could also be related to $\mathrm{BC}$ risk independent of effects on weight.

Mechanisms for the association we observed between gestational weight gain and risk of BBD are unclear, but studies by others may provide some insight. Among pregnant Swedish women, there was a significant association between progesterone level and gestational weight gain [46]. In a cross-sectional investigation of maternal and cord blood, mother's weight gain during pregnancy was associated with methylation (of IGF2 gene) patterns in maternal blood [47], and these maternal patterns of methylation were associated with folate, B12 and methylation in cord blood. Thus, gestational weight gain likely has a number of pathways for impacting the child, including a common genetic susceptibility to adiposity [48].

The longitudinal design of this investigation comprises its major strength. The earliest life exposure variables were reported by mothers as soon as 9 years after childbirth, long before the reporting of daughters' BBD, in our large cohort of girls from all over the US. Heights and weights of the girls, at 9yr and later, were reported in real time. Any misclassifications due to errors in reporting early life factors or childhood height and weight are likely nondifferential with respect to subsequent BBD, but may attenuate estimated associations between these factors and BBD. Though all models controlled for participant's age, and other potential confounders were included in multivariable-adjusted models, some residual and unmeasured confounding may remain. We cannot exclude the possibility of incomplete adjustment, or confounding through variables not considered, but little is known about childhood risk factors for BBD. Because our participants are all daughters of nurses, this reduces confounding by socioeconomic and other unmeasured factors, while enhancing the accuracy of the data. Although our cohort is not representative of US females, the comparison of risks within our cohort should still be valid and generalizable [49]. However, the racial/ethnic makeup of our cohort (95\% white/non-Hispanic) hinders race/ethnic groupspecific analyses and generalization to these other races/ethnicities.

In conclusion, we assessed the relationship between biopsy-confirmed BBD in young women and body size factors from very early life through adolescence, a period critical for 
the development of BC and other adult diseases. From girls born in the 1980's, we found evidence that four body size measures had strong independent associations with BBD; maternal gestational weight gain $\geq 20$ pounds produced daughters at lower risk, adiposity at $10 \mathrm{yr}$ was associated with lower risk, but 10yr height and peak adolescent height growth velocity were associated with increased risk. Continued follow-up of this cohort will be critical to re-assess these results as new cases of $\mathrm{BBD}$, and eventually cases of $\mathrm{BC}$, are diagnosed.

\section{Acknowledgments}

\section{Funding}

Supported by a grant from The Breast Cancer Research Foundation (NYC, NY) and by DK046834 from the National Institutes of Health (Bethesda, MD). Dr. Frazier was supported by an award from the American Institute for Cancer Research. Dr. Colditz, who founded GUTS, was supported, in part, by an American Cancer Society Clinical Research Professorship. The authors appreciate the ongoing, since 1996, dedication of our female GUTS participants and their mothers in NHSII.

\section{References}

1. Colditz GA, Frazier AL. Models of breast cancer show that risk is set by events of early life: prevention efforts must shift focus. Cancer Epidemiol Biomarkers Prev. 1995; 4:567-71. [PubMed: 7549816]

2. Buell P. Changing incidence of breast cancer in Japanese-American women. J Natl Cancer Inst. 1973; 51:1479-83. [PubMed: 4762931]

3. Land CE, Tokunaga M, Koyama K, Soda M, Preston DL, Nishimori I, et al. Incidence of female breast cancer among atomic bomb survivors, Hiroshima and Nagasaki, 1950-1990. Radiat Res. 2003; 160:707-17. [PubMed: 14640793]

4. Ziegler RG, Hoover RN, Pike MC, Hildesheim A, Nomura AM, West DW, et al. Migration patterns and breast cancer risk in Asian-American women. J Natl Cancer Inst. 1993; 85:1819-27. [PubMed: 8230262]

5. Berkey CS, Frazier AL, Gardner JD, Colditz GA. Adolescence and breast carcinoma risk. Cancer. 1999; 85:2400-9. [PubMed: 10357411]

6. Colditz GA, Bohlke K, Berkey CS. Breast cancer risk accumulation starts early: prevention must also. Breast Cancer Res Treat. 2014; 145:567-79. [PubMed: 24820413]

7. Trichopoulos D. Hypothesis: does breast cancer originate in utero? Lancet. 1990; 355:939-40.

8. Hilakivi-Clarke L, Clarke R, Lippman ME. Perinatal factors increase breast cancer risk. Breast Cancer Research \& Treatment. 1994; 31:273-284. [PubMed: 7881105]

9. Moley KH, Colditz GA. Effects of obesity on hormonally driven cancer in women. Sci Transl Med. 2016; 8:323ps3.

10. Michels KB, Xue F. Role of birthweight in the etiology of breast cancer. Int J Cancer. 2006; 119:2007-2025. [PubMed: 16823839]

11. Xue F, Michels KB. Intrauterine factors and risk of breast cancer: a systematic review and metaanalysis of current evidence. Lancet Oncology. 2007; 8:1088-1100. [PubMed: 18054879]

12. Wilson KM, Willett WC, Michels KB. Mothers' pre-pregnancy BMI and weight gain during pregnancy and risk of breast cancer in daughters. Breast Cancer Res Treat. 2011; 130:273-9. [PubMed: 21597917]

13. Ruder EH, Dorgan JF, Kranz S, Kris-Etherton PM, Hartman TJ. Examining breast cancer growth and lifestyle risk factors: early life, childhood, and adolescence. Clin Breast Cancer. 2008; 8:344 42.

14. Baer HJ, Tworoger SS, Hankinson SE, Willett WC. Body fatness at young ages and risk of breast cancer througout life. AJE. 2010; 171:1183-1194. 
15. Colditz G, Eliassen H, Toriola A, Hankinson S, Willett W, Rosner B. Weight change across the life-course and breast cancer risk among pre and postmenopausal women. Cancer Research. 2016; 76(S4) Abstract P1-07-05.

16. Ahlgren M, Melbye M, Wohlfahrt J, Sorensen TI. Growth patterns and the risk of breast cancer in women. NEJM. 2004; 351:1619-26. [PubMed: 15483280]

17. De Stavola BL, dos Santos Silva I, McCormack V, Hardy RJ, Kuh DJ, Wadsworth ME. Childhood growth and breast cancer. Am J Epidemiol. 2004; 159:671-682. [PubMed: 15033645]

18. Dyrstad W, Yan Y, Fowler A, Colditz G. Breast cancer risk associated with benign breast disease: systematic review and meta-analysis. Breast Cancer Research \& Treatment. 2015; 149:569-575. [PubMed: 25636589]

19. Baer H, Schnitt SJ, Connoly JL, Byrne C, Willett WC, Rosner B, Colditz GA. Early life factors and incidence of proliferative benign breast disease. Cancer Epidemiol Biomarkers Prev. 2005; 14:2889-97. [PubMed: 16365006]

20. Berkey CS, Rosner B, Willett WC, Tamimi RM, Frazier AL, Colditz GA. Prenatal factors and infant feeding in relation to risk of BBD in young women. Breast Cancer Research \& Treatment. 2015; 154:573-82. [PubMed: 26582399]

21. Berkey CS, Willett WC, Frazier AL, Rosner B, Tamimi RM, Colditz GA. Prospective study of growth and development in older girls and risk of benign breast disease in young women. Cancer. 2011; 117:1612-20. [PubMed: 21328325]

22. Colditz GA, Hankinson SE. The Nurses' Health Study: Lifestyle and health among women. Nat Rev Cancer. 2005; 5:388-96. [PubMed: 15864280]

23. Berkey CS, Rockett HRH, Gillman MW, Colditz GA. One-year changes in activity and in inactivity among 10- to 15-year old boys and girls. Relationship to change in BMI. Pediatrics. 2003; 111:836-843. [PubMed: 12671121]

24. Neinstein LS. Breast disease in adolescents and young women. Pediatr Clin North Am. 1999; 46:607-629. [PubMed: 10384810]

25. Su X, Colditz GA, Willett WC, Collins LC, Schnitt SJ, Connolly JL, et al. Genetic variation and circulating levels of IGF-I and IGFBP-3 in relation to risk of proliferative benign breast disease. International Journal of Cancer. 2010; 126:180-90. [PubMed: 19551864]

26. Tomeo CA, Rich-Edwards JW, Michels KB, Berkey CS, Hunter DJ, Frazier AL, Willett WC, Buka SL. Reproducibility and validity of maternal recall of pregnancy-related events. Epidemiology. 1999; 10:774-7. [PubMed: 10535796]

27. Troy LM, Michels KB, Hunter DJ, Spiegelman D, Manson JE, Colditz GA, Stampfer MJ, Willett WC. Self-reported birthweight and history of having been breastfed among younger women: an assessment of validity. Int J Epidemiol. 1996; 25:122-7. [PubMed: 8666479]

28. McClure CK, Bodnar LM, Ness R, Catov JM. Accuracy of maternal recall of gestational weight gain 4 to 12 years after delivery. Obesity (Silver Spring) 2011. 2011; 19:1047-53.

29. Strauss RS. Comparison of measured and self-reported weight and height in a cross-sectional sample of young adolescents. Int J Obes Relat Metab Disord. 1999; 23:904-908. [PubMed: 10490794]

30. Goodman E, Hinden BR, Khandelwal S. Accuracy of teen and parental reports of obesity and body mass index. Pediatrics. 2000; 106:52-58. [PubMed: 10878149]

31. Stunkard, AJ., Sorensen, T., Schulsinger, F. Use of the Danish Adoption Register for the study of obesity and thinness. In: Kety, SS.Rowland, LP.Sidman, RL., et al., editors. The Genetics of Neurological and Psychiatric Disorders. New York, NY: Raven Press; 1983. p. 115-120.

32. Must A, Willett WC, Dietz WH. Remote recall of childhood height, weight, and body build by elderly subjects. Am J Epidemiol. 1993; 138:56-64. [PubMed: 8333427]

33. Berkey CS, Gardner JD, Frazier AL, Colditz GA. Relation of childhood diet and body size to menarche and adolescent growth in girls. Am J Epidem. 2000; 152:446-452.

34. Berkey CS, Wang X, Dockery DW, Ferris BG Jr. Adolescent height growth in a US population. Ann Hum Biol. 1994; 21:435-42. [PubMed: 7985992]

35. Bock, RD., Thissen, D. Statistical problems of fitting individual growth curves. In: Johnston, FE.Roche, AF., Susanne, C., editors. Human Physical Growth \& Maturation: Methodologies and Factors. London, UK: Plenum Press; 1980. p. 265-290. 
36. SAS Institute Inc. Proc Logist. Cary, NC: SAS Institute Inc; 1997. SAS/STAT Software: Changes and Enhancements Through Release 6.12.

37. Berkey CS, Tamimi RM, Willett WC, Rosner B, Frazier AL, Colditz GA. Adolescent physical activity and inactivity: A prospective study of risk of benign breast disease in young women. Breast Cancer Research \& Treatment. 2014; 146:611-618. [PubMed: 25034340]

38. Gillman MW, Rifas-Shiman S, Berkey CS, Field AE, Colditz GA. Maternal gestational diabetes, birth weight, and adolescent obesity. Pediatrics. 2003; 111:e221-6. [PubMed: 12612275]

39. Stuebe AM, Forman MR, Michels KB. Maternal recalled gestational weight gain, pre-pregnancy BMI, and obesity in daughter. Int J Obes (London). 2009; 33:743-752. [PubMed: 19528964]

40. Roberts CT, Brown AL, Graham DE, Seelig S, Berry S, Gabbay KH, Rechler MM. Growth hormone regulates the abundance of insulin-like growth factor 1 RNA in adult rat liver. J Biol Chem. 1986; 261:10025-8. [PubMed: 3755433]

41. Calle EE, Kaaks R. Overweight, obesity and cancer: epidemiological evidence and proposed mechanisms. Nature Reviews Cancer. 2004; 4:579-591. [PubMed: 15286738]

42. Cousminer DL, Berry DJ, Timpson NJ, Ang W, Thiering E, et al. Genome-wide association and longitudinal analyses reveal genetic loci linking pubertal height growth, pubertal timing and childhood adiposity. Human Molecular Genetics. 2013; 22:2735-2747. [PubMed: 23449627]

43. Bertrand KA, Baer HJ, Orav EJ, Klifa C, et al. Body fatness during childhood and adolescence and breast density in young women: a prospective analysis. Breast Cancer Res. 2015; 17:95. [PubMed: 26174168]

44. Anderson ZJ, Baker JL, Bihrmann K, Vejborg I, Sorensen TI, Lynge E. Birth weight, childhood body mass index, and height in relation to mammographic density and breast cancer: a registerbased cohort study. Breast Cancer Research. 2014; 16:R4. [PubMed: 24443815]

45. Warrington NM, Howe LD, Paternoster LO, Kaakinen M, Herrala S, et al. A genome-wide association study of body mass index across early life and childhood. Int J Epi. 2015; 44:700-712.

46. Lof M, Hilakivi-Clarke L, Sandin SS, de Assis S, Yu W, Weiderpass E. Dietary fat intake and gestational weight gain in relation to estradiol and progesterone plasma levels during pregnancy: a longitudinal study in Swedish women. BMC Womens Health. 2009; 9:10. [PubMed: 19402915]

47. Ba Y, Yu H, Geng X, Zhu C, Zhu Q, Zheng T, Ma S, Wang G, Li Z, Zhang Y. Relationship of folate, vitamin B12 and methylation of insulin-like growth factor-II in maternal and cord blood. Eur J Clin Nutr. 2011; 65:480-5. [PubMed: 21245875]

48. Gao C, Patel CJ, Michailidou K, Peters U, Gong J, Schildkraut J, et al. Mendelian randomization study of adiposity-related traits and risk of breast, ovarian, prostate, lung and colorectal cancer. Int J Epidemiol. 2016 Jul 17. pii: dyw129. [Epub ahead of print].

49. Willett WC, Blot WJ, Colditz GA, Folsom AR, Henderson BE, Stampfer MJ. Merging and emerging cohorts: Not worth the wait. Nature. 2007; 445:257-8. [PubMed: 17230171] 


\section{TABLE 1}

Characteristics of girls in the Growing Up Today Study, according to tertile of their Body Mass Index at age 10yr. Girls (N=4455) were born between 1985 and 1987. Shown below are Mean or \% within each tertile.

\begin{tabular}{|c|c|c|c|}
\hline & \multicolumn{3}{|c|}{ Body Fatness (BMI) Tertile at age $10 \mathrm{yr}$} \\
\hline & $\leq 16.51 \mathrm{~kg} / \mathrm{m}^{2}$ & $\underline{16.51-18.98 \mathrm{~kg} / \mathrm{m}^{2}}$ & $\geq 18.98 \mathrm{~kg} / \mathrm{m}^{2}$ \\
\hline No. of girls & 1488 & 1481 & 1486 \\
\hline \multicolumn{4}{|l|}{ Characteristic } \\
\hline Exact Age (yr) for 10yr data & 10.71 & 10.85 & 10.88 \\
\hline BMI at $10 \mathrm{yr}\left(\mathrm{kg} / \mathrm{m}^{2}\right)$ & 15.20 & 17.67 & 21.84 \\
\hline Pictogram at $10 \mathrm{yr}(1-9)$ & 2.94 & 3.65 & 4.71 \\
\hline Height at $10 \mathrm{yr}$ (in) & 56.2 & 57.1 & 58.0 \\
\hline Weight at $10 \mathrm{yr}(\mathrm{lb})$ & 68.4 & 82.3 & 105.0 \\
\hline Physical Activity 10yr (hrs/day) & 1.31 & 1.34 & 1.25 \\
\hline Maternal Height (in) & 64.9 & 64.9 & 64.9 \\
\hline Maternal Pre-pregnancy BMI & 21.4 & 22.1 & 23.5 \\
\hline Paternal Height (in) & 70.8 & 70.9 & 70.8 \\
\hline Gestational Weight Gain (lbs) & 30.3 & 31.4 & 32.0 \\
\hline Birth Weight (lbs) & 7.4 & 7.6 & 7.7 \\
\hline Birth Length (in) & 20.0 & 20.2 & 20.2 \\
\hline Birth BMI $\left(\mathrm{kg} / \mathrm{m}^{2}\right)$ & 13.0 & 13.2 & 13.3 \\
\hline PHV (in/yr) & 3.43 & 3.40 & 3.36 \\
\hline Peak Age (yr) & 12.0 & 11.85 & 11.76 \\
\hline Age at Menarche (yr) & 13.3 & 12.8 & 12.4 \\
\hline Adult Height (in) & 65.3 & 65.2 & 65.24 \\
\hline Weight at $18 \mathrm{yr}(\mathrm{lb})$ & 123.4 & 133.3 & 154.5 \\
\hline BMI at $18 \mathrm{yr}\left(\mathrm{kg} / \mathrm{m}^{2}\right)$ & 20.3 & 22.00 & 25.49 \\
\hline Height growth (in) $10-18 \mathrm{yr}$ & 9.97 & 8.91 & 8.00 \\
\hline Weight change (lb) $10-18 \mathrm{yr}$ & 57.8 & 54.3 & 53.2 \\
\hline BMI change $10-18 \mathrm{yr}$ & 5.41 & 4.67 & 3.97 \\
\hline GUTS BBD (young adulthood) & $2.2 \%$ & $1.3 \%$ & $1.3 \%$ \\
\hline Maternal BC & $4.6 \%$ & $5.9 \%$ & $5.7 \%$ \\
\hline Maternal BBD & $18.6 \%$ & $18.9 \%$ & $15.6 \%$ \\
\hline Maternal BC and BBD & $1.01 \%$ & $1.35 \%$ & $1.48 \%$ \\
\hline
\end{tabular}

Breast Cancer Res Treat. Author manuscript; available in PMC 2018 February 01. 


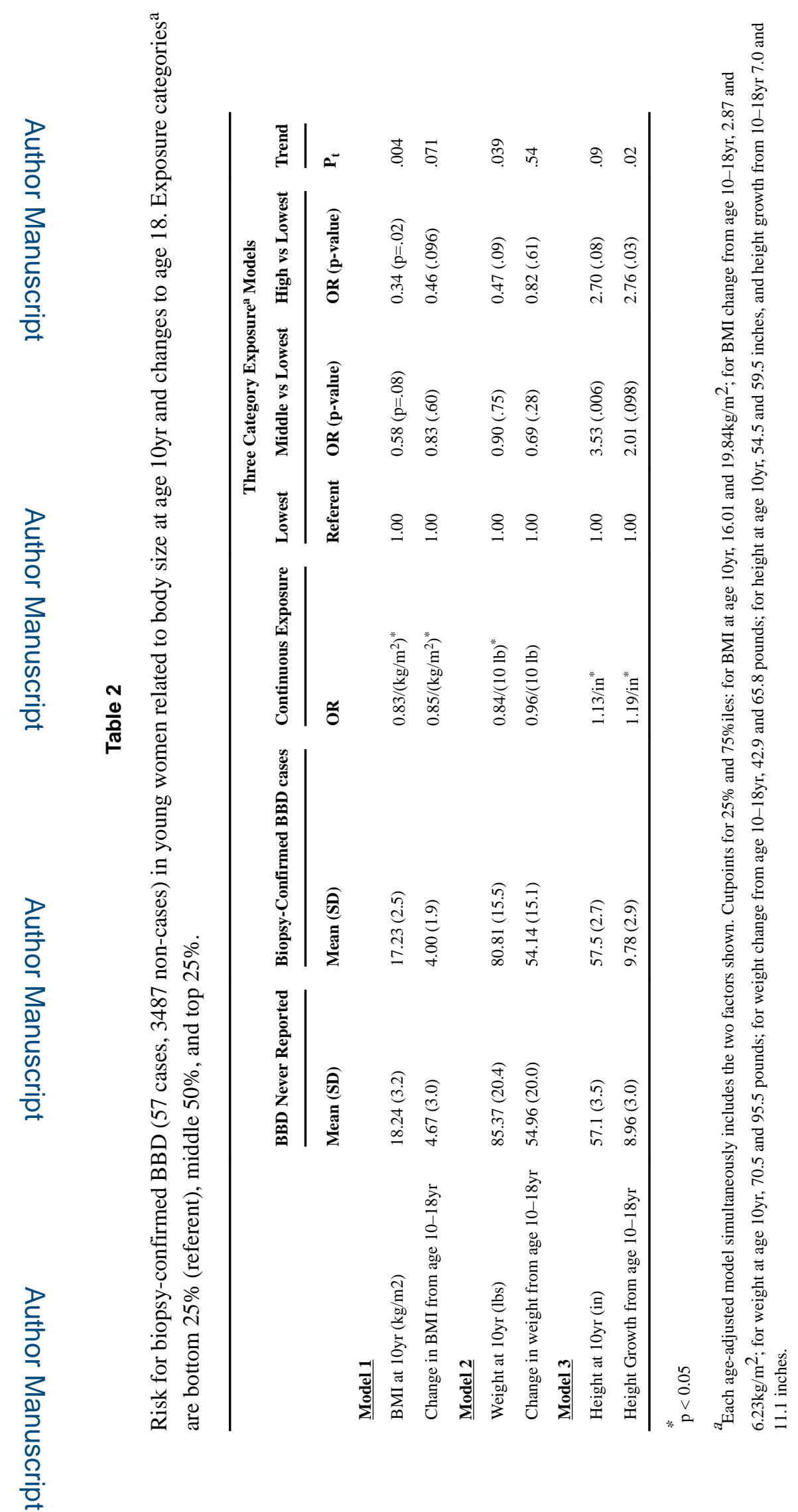

Breast Cancer Res Treat. Author manuscript; available in PMC 2018 February 01. 


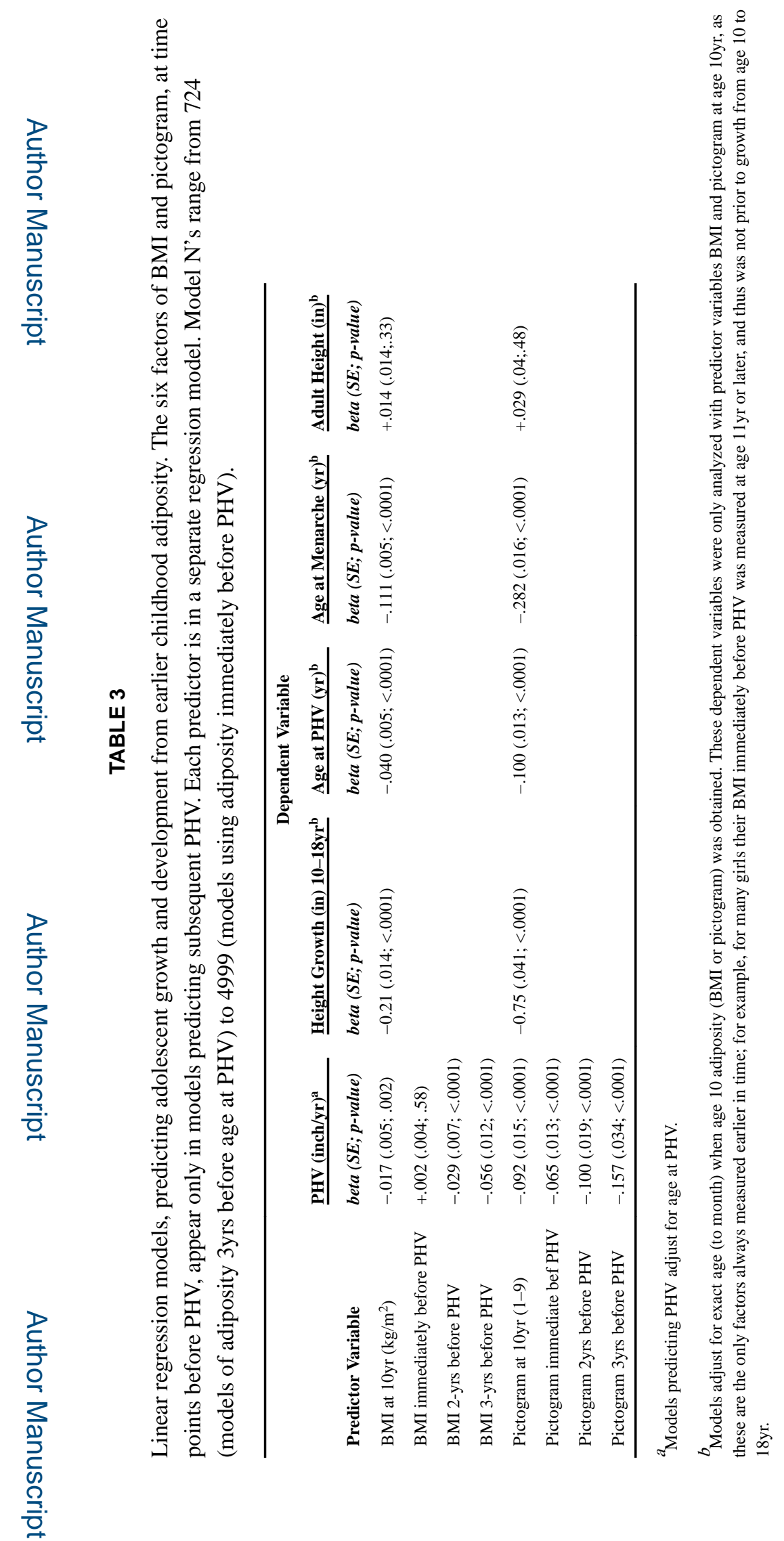

Breast Cancer Res Treat. Author manuscript; available in PMC 2018 February 01. 


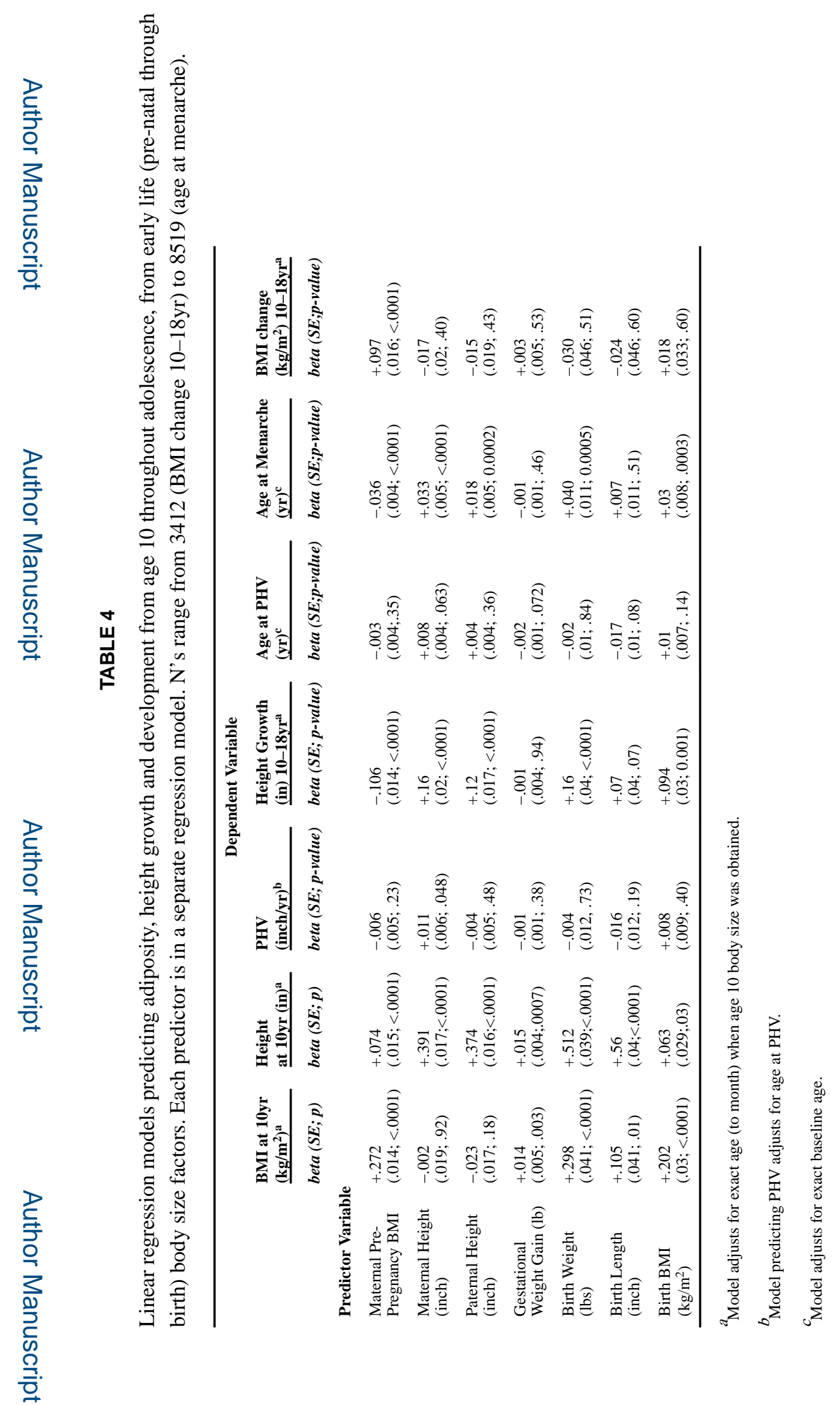

Breast Cancer Res Treat. Author manuscript; available in PMC 2018 February 01. 


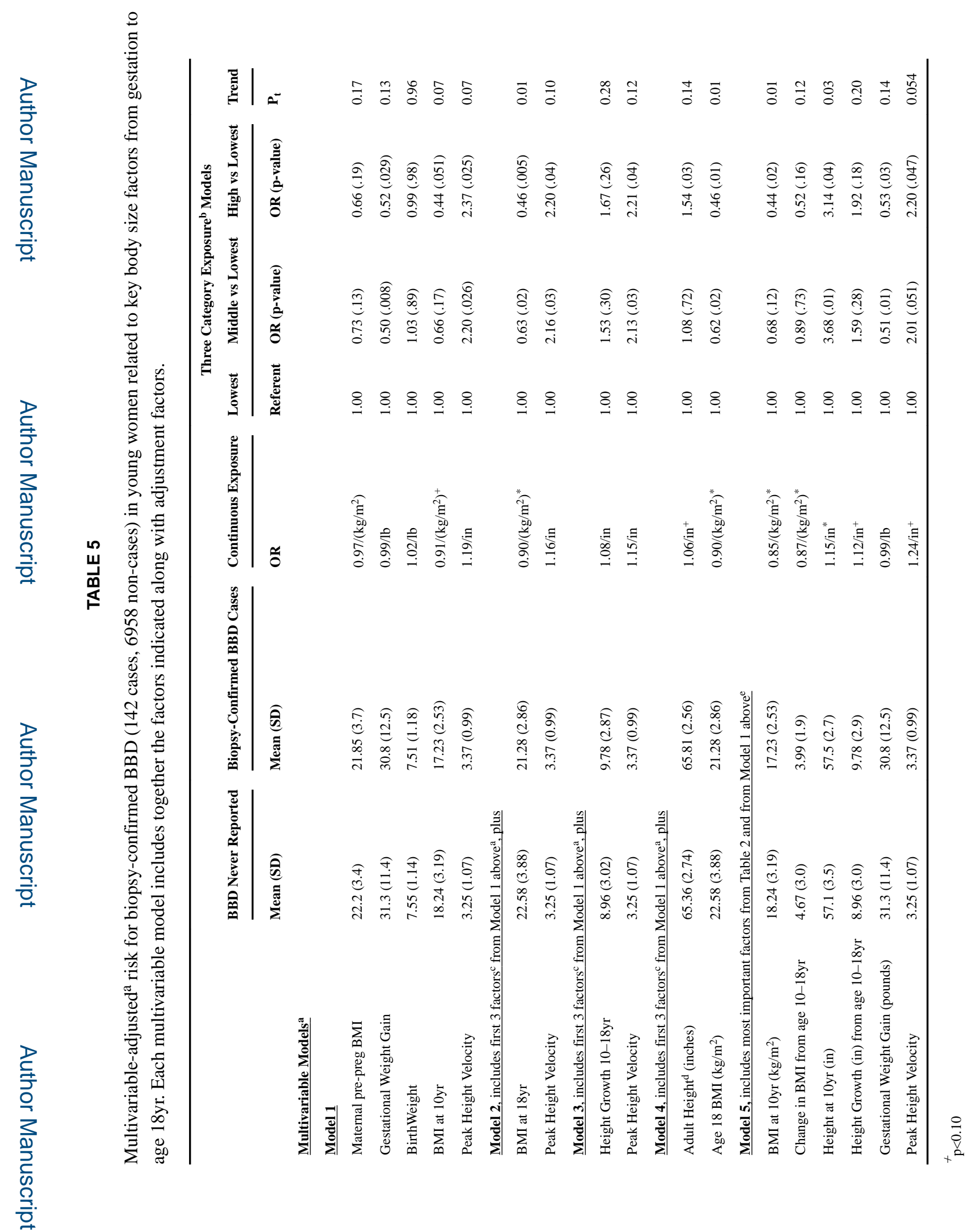

Breast Cancer Res Treat. Author manuscript; available in PMC 2018 February 01. 
Berkey et al.

Page 17

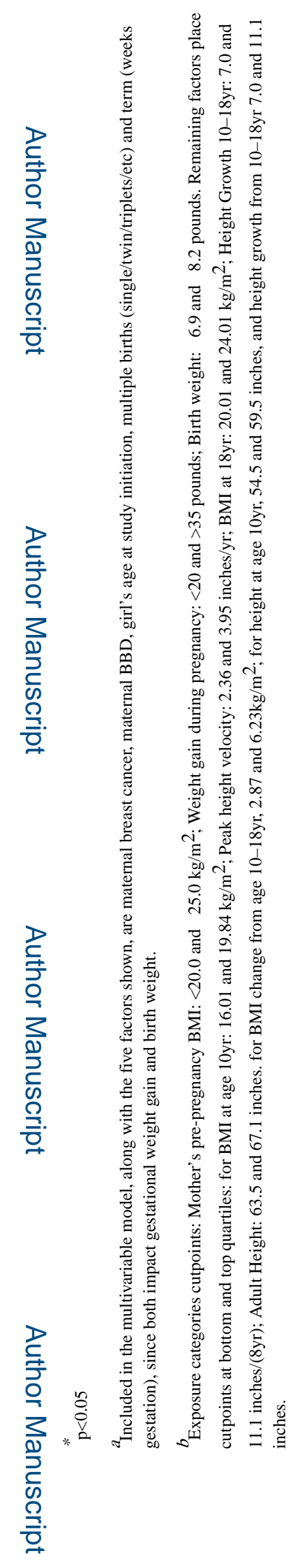

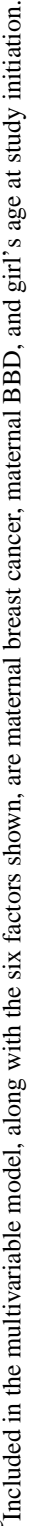

Breast Cancer Res Treat. Author manuscript; available in PMC 2018 February 01. 